\title{
Nickel Hydride Catalyzed Cleavage of Allyl Ethers Induced by Isom- erization
}

\author{
Prasad M. Kathe \\ Andreas Berkefeld*b \\ Ivana Fleischer*a (iD) \\ a Institute of Organic Chemistry, Faculty of Science and Mathematics, \\ Eberhard Karls University Tübingen, Auf der Morgenstelle 18, \\ 72076 Tübingen, Germany \\ ivana.fleischer@uni-tuebingen.de \\ b Institute of Inorganic Chemistry, Faculty of Science and Mathematics, \\ Eberhard Karls University Tübingen, Auf der Morgenstelle 18 \\ 72076 Tübingen, Germany \\ andreas.berkefeld@uni-tuebingen.de \\ Published as part of the Cluster \\ Modern Nickel-Catalyzed Reactions
}

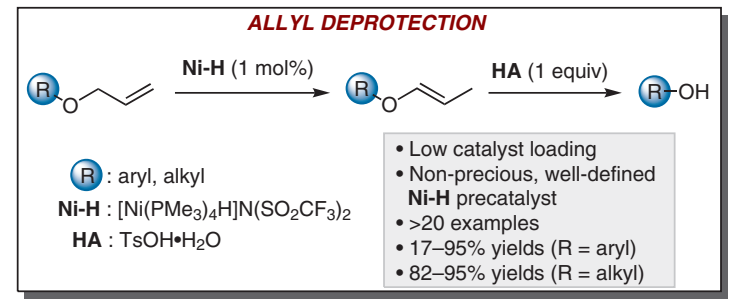

demonstrated in several total syntheses of natural compounds. ${ }^{4}$ These reactions usually follow two main mechanisms. The first is based on the formation of a metal allyl intermediate by oxidative addition in the presence of a nucleophile or reducing agent. ${ }^{5}$ The underlying principle in other cases is an initial olefin isomerization (single-bond transposition) to an enol ether, followed by hydrolysis. ${ }^{6} \mathrm{Al}-$ though the isomerization of allylic alcohols, ethers, and related substrates has been studied extensively, ${ }^{7}$ its application or suggested involvement in the deallylation is much less well investigated. Furthermore, the use of nonprecious metals in allyl deprotection methods is rare but clearly desirable.

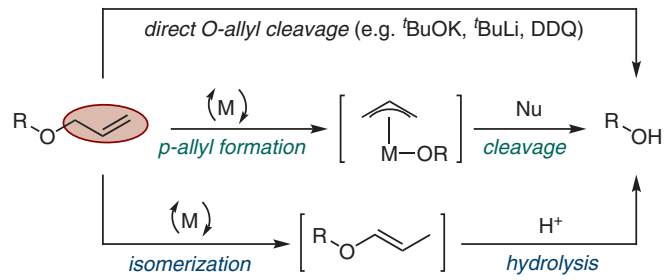

Allyl protecting group:

$\checkmark$ versatile

$\checkmark$ easy installation $\checkmark$ ideal late-stage removal

Scheme 1 General principle and deallylation methodologies

An important feature in deprotection chemistry is the concept of orthogonality, based on the selective removal of a protecting group through differential reactivity and stability. ${ }^{8}$ Recently, Yamada and co-workers reported an elegant method for orthogonal oxidative deprotection of $p$ methylbenzyl ethers in the presence of a $p$-methoxybenzyl group, and vice-versa. ${ }^{9}$ In this context, the chemoselective removal of an allyl group in the presence of a benzyl protecting group is of interest. 
During our investigations of nickel hydride/ Brønsted acid catalyzed tandem reactions of allyl ethers for the generation of oxacyclic scaffolds, we observed an unexpected loss of an allyl group under the reaction conditions in some cases. ${ }^{10}$ A plausible explanation was an initial isomerization to form an alkenyl ether, as later proven by independent experiments, and subsequent acidic hydrolysis owing to the presence of water in the acid.

Having obtained this result and based on our interest in isomerization reactions ${ }^{11}$ and nickel catalysis, ${ }^{12}$ we envisaged developing a general catalytic process for O-deallylation of ethers. To investigate this further, we chose the Oallylated phenol 1a as a substrate and the complex nickel hydride $\left[\mathrm{Ni}\left(\mathrm{PMe}_{3}\right)_{4} \mathrm{O}\right] \mathrm{N}\left(\mathrm{SO}_{2} \mathrm{CF}_{3}\right)_{2}$ from our original study as a precatalyst, due to its structural simplicity (Table 1 ). The precatalyst can by synthesized in two steps from bis(cycloocta-1,5-dienyl)nickel(0), the appropriate ligand, and bistriflimidic acid on a gram scale, and can be stored under argon on the bench. ${ }^{13}$ In line with our previous investigations, partial isomerization to the corresponding enol ether occurred. This was followed by subsequent addition of a Brønsted acid in an attempt to obtain 2-methoxyphenol (2a). Initial experiments using catalytic amounts of diphenylphosphoric and triflic acid gave only a mixture of the starting material and its isomer (Table 1, entries 1 and 2). Increasing the amount of precatalyst and the use of a weaker acid gave only traces of $\mathbf{2 a}$ (entries 3 and 4). The use of triflic acid (10 mol\%) with a prolonged reaction time led to formation of $\mathbf{2 a}$ in a moderate yield of $38 \%$ (entry 5 ).

Upon screening of additional Brønsted acids, we found that a stoichiometric amount of $p$-toluenesulfonic acid monohydrate $\left(\mathrm{TsOH} \cdot \mathrm{H}_{2} \mathrm{O}\right)$ gave complete conversion into the phenol (isolated yield 73\%) within 30 minutes (Table 1 , entry 6). $\mathrm{TsOH} \cdot \mathrm{H}_{2} \mathrm{O}$ is an attractive option owing to its bench stability, its ease of handling, and its straightforward removal through aqueous workup, after which the product 2a was determined to be spectroscopically pure without the need for column chromatographic purification. This reaction was also demonstrated at $5 \mathrm{mmol}$ scale (entry 6 ). A control experiment with $\mathrm{TsOH} \cdot \mathrm{H}_{2} \mathrm{O}$ in the absence of the catalyst led to complete recovery of unreacted 1a (entry 7). The precatalyst loading could be decreased to $0.5 \mathrm{~mol} \%$ without any loss in activity (entry 8). Unfortunately, longer reaction times were deemed necessary to achieve complete conversion when 0.5 equiv of TsOH. $\mathrm{H}_{2} \mathrm{O}$ were used (entry 9 ), and only traces of product were detected when using 1 mol\% of acid (entry 10). In addition, we examined whether a catalytic amount of acid could be used in the presence of water to promote the hydrolysis, but we found this not to be the case (entry 11). Addition of all components at the onset of the reaction resulted in 1:1 mixture of $\mathbf{1 a}$ and $\mathbf{2 a}$ (entry 12). Furthermore, the use of slightly weaker camphorsulfonic acid (CSA) required longer reaction times for complete conversion (entry 13).
Table 1 Optimization of the Reaction Conditions for the Ni-Catalyzed Deallylation $^{\mathrm{a}}$

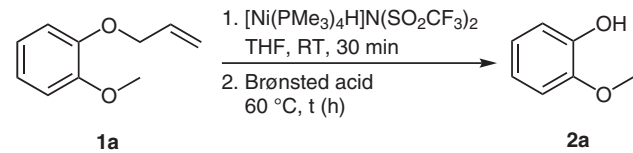

\begin{tabular}{cllll}
\hline Entry & $\mathrm{Ni}-\mathrm{H}(\mathrm{mol} \%)$ & Acid $(\mathrm{mol} \%)$ & Time $(\mathrm{h})$ & Yield $^{\mathrm{b}}(\%)$ of $2 \mathrm{a}$ \\
\hline 1 & 1 & $(\mathrm{PhO})_{2} \mathrm{P}(\mathrm{O}) \mathrm{OH}(8)$ & 1 & $-\mathrm{c}$ \\
2 & 1 & $\mathrm{MeSO}_{3} \mathrm{H}(8)$ & 1 & $-\mathrm{c}$ \\
3 & 5 & $(\mathrm{PhO})_{2} \mathrm{P}(\mathrm{O}) \mathrm{OH}(120)$ & 0.5 & traces \\
4 & 5 & $(\mathrm{PhO})_{2} \mathrm{P}(\mathrm{O}) \mathrm{OH}(200)$ & 0.5 & traces \\
$5^{\mathrm{d}}$ & 2 & $\mathrm{~F}_{3} \mathrm{CSO}{ }_{3} \mathrm{H}(10)$ & 15 & 38 \\
6 & 1 & $\mathrm{TsOH} \cdot \mathrm{H}_{2} \mathrm{O}(100)$ & 0.5 & $73(79)^{\mathrm{e}}$ \\
7 & - & $\mathrm{TsOH} \cdot \mathrm{H}_{2} \mathrm{O}(100)$ & 1 & $-\mathrm{f}$ \\
8 & 0.5 & $\mathrm{TsOH} \cdot \mathrm{H}_{2} \mathrm{O}(100)$ & 1 & 84 \\
9 & 0.5 & $\mathrm{TsOH} \cdot \mathrm{H}_{2} \mathrm{O}(50)$ & 15 & 75 \\
10 & 1 & $\mathrm{TsOH} \cdot \mathrm{H}_{2} \mathrm{O}(1)$ & 1 & traces \\
$11^{9}$ & 0.5 & $\mathrm{TsOH} \cdot \mathrm{H}_{2} \mathrm{O}(10)$ & 5 & traces \\
$12^{\mathrm{h}}$ & 0.5 & $\mathrm{TsOH} \cdot \mathrm{H}_{2} \mathrm{O}(100)$ & 1 & $(1: 1)^{\mathrm{i}}$ \\
13 & 1 & $\mathrm{CSA}(100)$ & 5 & $(1: 4)^{\mathrm{i}}$ \\
\hline
\end{tabular}

a Reaction conditions: 1a $(0.25 \mathrm{mmol}),\left[\mathrm{Ni}\left(\mathrm{PMe}_{3}\right)_{4} \mathrm{H}\right] \mathrm{N}\left(\mathrm{SO}_{2} \mathrm{CF}_{3}\right)_{2}$, Brønsted acid, $\operatorname{THF}(0.16 \mathrm{M}), 30 \mathrm{~min}$, RT with $\mathrm{Ni}-\mathrm{H}$, then $60^{\circ} \mathrm{C}$ for the indicated time with acid.

b Isolated yield.

c Mixture of olefin isomers (unreacted 1a along with enol ethers).

d 30 min at RT with $\mathrm{Ni}-\mathrm{H}$ then $15 \mathrm{~h}$ at $\mathrm{RT}$ with $\mathrm{F}_{3} \mathrm{CSO}_{3} \mathrm{H}$.

e Yield at $5 \mathrm{mmol}$ scale.

$\mathbf{1}$ a was recovered.

$g$ With $\mathrm{H}_{2} \mathrm{O}$ (1 equiv).

${ }^{\mathrm{h}}$ All reaction components were added at the start.

i Ratio $1 \mathrm{a} / 2 \mathrm{a}$ determined by ${ }^{1} \mathrm{H}$ NMR analysis.

Therefore, a system consisting of $1 \mathrm{~mol} \%$ of $\mathrm{Ni}-\mathrm{H}$ and 1 equivalent of $\mathrm{TsOH} \cdot \mathrm{H}_{2} \mathrm{O}$ was chosen for further study of the transformation. With an operationally simple and straightforward protocol in hand, we proceeded to evaluate its generality through deprotection of a variety of substituted Oallylated compounds, starting with aryl allyl ethers $\mathbf{1 b}-\mathbf{p}$ (Scheme 2). First, the influence of substituents in the 3- and 4-positions of the phenyl ring was evaluated. Compounds containing electron-donating groups performed much better under the catalytic conditions than those with electronwithdrawing substituents. Ethers 1c, 1g, 1h, 11, and 1n were smoothly deallylated to the corresponding phenols in yields of $68-95 \%$. Note that no column chromatographic purification was necessary to obtain phenols $\mathbf{2 c}$ and $\mathbf{2 g}$ in adequate purity (>95\%). The boronate ester 1d was converted in a satisfactory $73 \%$ yield, albeit with a longer reaction time of 20 hours. The 4-trifluoromethylsulfanyl ether $\mathbf{1 f}$ underwent deallylation to give $\mathbf{2 f}$ in $34 \%$ yield. Upon testing the halide-substituted ethers $\mathbf{1 b}, \mathbf{1} \mathbf{m}$, and $\mathbf{1 0}$, we obtained the corresponding phenols in low to moderate yields of 56 , 
18 , and $37 \%$, respectively. A competing dehalogenation was not observed; low yields are therefore attributable to lower reactivity in both steps. Note that the isomerization to an enol ether was more closely investigated in our previous work; although it was never complete (usually 50\%), it did not impact the overall yield if both reactions were successful.

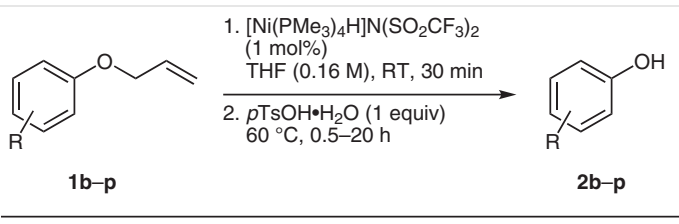

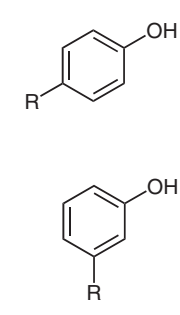

2I, $\mathrm{R}=\mathrm{OMe}, 86 \%^{\mathrm{a}}$

$2 \mathrm{~m}, \mathrm{R}=\mathrm{F}, 18 \%{ }^{\mathrm{b}}$

2n, $\mathrm{R}=\mathrm{Et}, 68 \%^{\mathrm{a}}$

2o, $\mathrm{R}=\mathrm{Br}, 37 \%^{\mathrm{b}}$

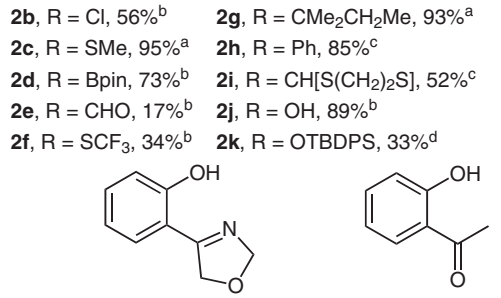

2 p, $62 \%{ }^{\mathrm{e}}$

$2 q, 87 \%$ b

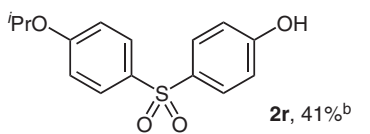

Scheme 2 Substrate scope of Ni-catalyzed deprotection of aryl allyl ethers. Reaction time for the second step: ${ }^{\mathrm{a}} 6 \mathrm{~h},{ }^{\mathrm{b}} 15 \mathrm{~h},{ }^{\mathrm{c}} 10 \mathrm{~h},{ }^{\mathrm{d}} 22 \mathrm{~h}$ [camphersulfonic acid (1 equiv)], e $15 \mathrm{~h}\left[\mathrm{TsOH} \cdot \mathrm{H}_{2} \mathrm{O}\right.$ (2 equiv)].

Although the aldehyde 1e displayed poor reactivity and gave $\mathbf{2 e}$ in only $17 \%$ yield, its protected derivative $\mathbf{1 i}$ underwent deallylation to give a $52 \%$ yield of $\mathbf{2 i}$. The allyl group could be successfully removed from the monoprotected hydroquinone 1j. A selective allyl deprotection was observed in the presence of a tert-butyl(diphenyl)silyl group by using a weaker acid (CSA); however, the reaction was slow, and only a $33 \%$ yield of $\mathbf{2 k}$ was obtained.

In the presence of an oxazole motif, deallylation to the phenol 2p occurred in 62\% yield; an additional equivalent of TsOH. $\mathrm{H}_{2} \mathrm{O}$ was used in this case. In contrast to other substrates with electron-withdrawing groups, the 2-acetylsubstituted ether 1q was converted into the product in good yield (87\%). Moreover, it was found that a sulfone functionality, which is often found in biologically active compounds, can be present in the molecule, as $\mathbf{2 r}$ was obtained in $41 \%$ yield.

Primary, secondary and tertiary alkyl allyl ethers $\mathbf{3}$ also underwent facile $\mathrm{C}-\mathrm{O}$ bond cleavage (Scheme 3). The homobenzylic alcohol 4a, citronellol (4b), (-)-menthol (4c), and $\alpha$-terpenol (4d) were obtained from the corresponding allyl ethers in appreciable yields of $82-95 \%$. Note that the allyl protecting group was removed selectively in the presence of a benzyl group in the case of 4e. Moreover, the protected cholesterol derivative $\mathbf{3 f}$ gave cholesterol (4f) with- out any racemization in $84 \%$ yield. The internal double bonds in substrates $\mathbf{3 b}, \mathbf{4 d}$, and $\mathbf{4 f}$ did not isomerize during the transformation. It is noteworthy that, apart from $\mathbf{4 e}$, all aliphatic compounds were obtained in high yields without the need for chromatographic purification.

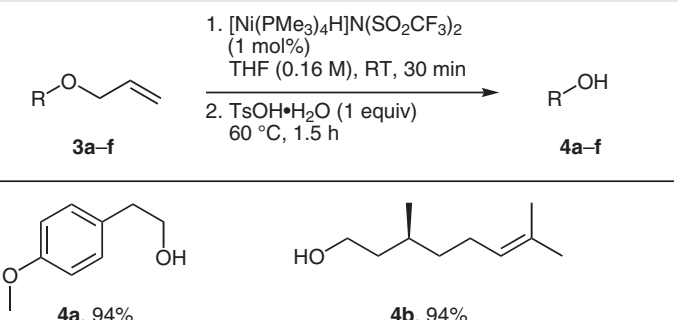

4b, $94 \%$<smiles>CC1CC[C@@H](C(C)C)[C@H](O)C1</smiles>

$4 c, 82 \%$<smiles>CC1=CCC(C(C)(C)O)CC1</smiles>

4d, $95 \%$
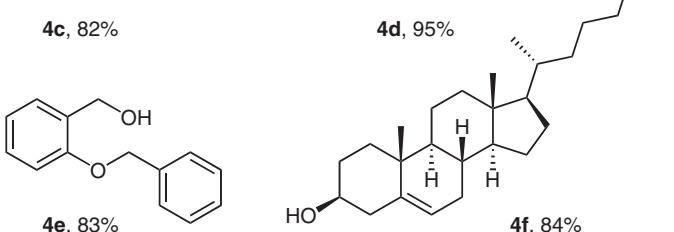

Scheme 3 Deallylation of alkyl allyl ethers: substrate scope

In addition, we also examined the feasibility of deallylation of amides, which has received less attention in the literature $^{14}$ despite its potential in, for example, the synthesis of immobilized DNA oligomers, where allyl groups are used to protect the nucleotide bases. ${ }^{15}$ Employing our 0 -deallylation method, the deprotection of $\mathrm{N}$-allylated benzamide $\mathbf{5}$ was possible and gave the corresponding product $\mathbf{6}$ in $48 \%$ yield (Scheme 4). To the best of our knowledge, there are no previous reports on the deallylation of amides by employing a nickel catalyst.<smiles>C=CCN(C)C(=O)c1ccccc1</smiles>

$$
\begin{aligned}
& \text { 1. }\left[\mathrm{Ni}\left(\mathrm{PMe}_{3}\right)_{4} \mathrm{H}\right] \mathrm{N}\left(\mathrm{SO}_{2} \mathrm{CF}_{3}\right)_{2} \\
& (1 \mathrm{~mol} \%) \\
& \text { THF }(0.16 \mathrm{M}), \mathrm{RT}, 30 \mathrm{~min} \\
& \hline \begin{array}{l}
\text { 2. } \mathrm{TsOH} \bullet \mathrm{H}_{2} \mathrm{O} \text { (1 equiv) } \\
60{ }^{\circ} \mathrm{C}, 15 \mathrm{~h}
\end{array}
\end{aligned}
$$

Scheme 4 Deprotection of amide 5
In summary, we have developed a rapid and straightforward protocol for a nickel hydride catalyzed, Brønsted acid promoted deprotection of allyl ethers. ${ }^{16}$ The transformation occurs through an initial nickel-catalyzed isomerization of the terminal double bond to the enol ether, which, in turn, is hydrolytically cleaved by the Brønsted acid. The deprotection of the allyl ether moiety occurs chemoselectively in the presence of internal double bonds and other protecting groups, such as the widely used benzyl group. The low catalyst loading along with the generality of the substrate 
scope, point to the robustness of the protocol, which is suitable for both aryl and alkyl ethers. Moreover, a deprotection of an $\mathrm{N}$-allylamide has been achieved.

\section{Funding Information}

Financial support from the German Academic Exchange Service New Delhi, the Deutscher Akademischer Austauschdienst (fellowship for P.K.), and the University of Tübingen is gratefully acknowledged.

\section{Supporting Information}

Supporting information for this article is available online at https://doi.org/10.1055/s-0040-1706683.

\section{References and Notes}

(1) (a) Wuts, P. G. M.; Greene, T. W. Greene's Protective Groups in Organic Synthesis, 4th ed; Wiley-Interscience: Hoboken, 2006, 16. (b) Weissman, S. A.; Zewge, D. Tetrahedron 2005, 61, 7833.

(2) Guibé, F. Tetrahedron 1997, 53, 13509.

(3) (a) Kitov, P. I.; Bundle, D. R. Org. Lett. 2001, 3, 2835. (b) Bailey, W. F.; England, M. D.; Mealy, M. J.; Thongsornkleeb, C.; Teng, L. Org. Lett. 2000, 2, 489. (c) Yadav, J. S.; Chandrasekhar, S.; Sumithra, G.; Kache, R. Tetrahedron Lett. 1996, 37, 6603. (d) Atienza, B. J. P.; Truong, N.; Williams, F. J. Org. Lett. 2018, 20, 6332.

(4) (a) Walia, M.; Teijaro, C. N.; Gardner, A.; Tran, T.; Kang, J.; Zhao, S.; O'Connor, S. E.; Courdavault, V.; Andrade, R. B. J. Nat. Prod. 2020, 83, 2425. (b) Liu, Z.; Meng, Y.; Yuan, P.; Wang, Z.; Gao, J.M.; Zheng, H. Org. Lett. 2020, 22, 520. (c) Praveen Kumar, V.; Kishi, Y.J. Am. Chem. Soc. 2020, 142, 14743.

(5) (a) Gärtner, D.; Konnerth, H.; von Wangelin, A. J. Catal. Sci. Technol. 2013, 3, 2541. (b) Tanaka, S.; Suzuki, Y.; Saburi, H.; Kitamura, M. Tetrahedron 2015, 71, 6559. (c) Vutukuri, D. R.; Bharathi, P.; Yu, Z.; Rajasekaran, K.; Tran, M.-H.; Thayumanavan, S. J. Org. Chem. 2003, 68, 1146. (d) Taniguchi, T.; Ogasawara, K. Angew. Chem. Int. Ed. 1998, 37, 1136. (e) Honda, M.; Morita, H.; Nagakura, I. J. Org. Chem. 1997, 62, 8932. (f) Mao, Y.; Liu, Y.; Hu, Y.; Wang, L.; Zhang, S.; Wang, W. ACS Catal. 2018, 8, 3016. (g) Hemming, D. S.; Talbot, E. P.; Steel, P. G. Tetrahedron Lett. 2017, 58, 17. (h) Chouhan, M.; Kumar, K.; Sharma, R.; Grover, V.; Nair, V. A. Tetrahedron Lett. 2013, 54, 4540. (i) Giedyk, M.; Turkowska, J.; Lepak, S.; Marculewicz, M.; ó Proinsias, K.; Gryko, D. Org. Lett. 2017, 19, 2670. (j) Meng, C.; Niu, H.; Ning, J.; Wu, W.; Yi, J. Molecules 2020, 25, 602.

(6) (a) Cadot, C.; Dalko, P. I.; Cossy, J. Tetrahedron Lett. 2002, 43, 1839. (b) Corey, E. J.; Suggs, J. W. J. Org. Chem. 1973, 38, 3224. (c) Varela-Álvarez, A.; Sordo, J. A.; Piedra, E.; Nebra, N.; Cadierno, V.; Gimeno, J. Chem. Eur. J. 2011, 17, 10583.
(7) (a) Huang, G.; Ke, M.; Tao, Y.; Chen, F. J. Org. Chem. 2020, 85, 5321; corrigendum: J. Org. Chem.; 2020, 85, 6830. (b) Gao, W.; Zhang, X.; Xie, X.; Ding, S. Chem. Commun. 2020, 56, 2012. (c) Trost, B. M.; Cregg, J. J.; Quach, N. J. Am. Chem. Soc. 2017, 139, 5133. (d) Bolyog-Nagy, E.; Udvardy, A.; Barczáné-Bertók, A.; Joó, F.; Kathó, A. Inorg. Chim. Acta 2017, 455, 514. (e) Li, H.; Mazet, C. J. Am. Chem. Soc. 2015, 137, 10720. (f) Erbing, E.; VázquezRomero, A.; Bermejo Gómez, A.; Platero-Prats, A. E.; Carson, F.; Zou, X.; Tolstoy, P.; Martín-Matute, B. Chem. Eur. J. 2016, 22, 15659 .

(8) Ghosh, B.; Kulkarni, S. S. Chem. Asian J. 2020, 15, 450.

(9) Ikeuchi, K.; Murasawa, K.; Ohara, K.; Yamada, H. Org. Lett. 2019, $21,6638$.

(10) Kathe, P. M.; Caciuleanu, A.; Berkefeld, A.; Fleischer, I. J. Org. Chem. 2020, 85, 15183.

(11) Kathe, P. M.; Fleischer, I. Org. Lett. 2019, 21, 2213.

(12) (a) Gehrtz, P. H.; Geiger, V.; Schmidt, T.; Sršan, L.; Fleischer, I. Org. Lett. 2019, 21, 50. (b) Gehrtz, P. H.; Kathe, P.; Fleischer, I. Chem. Eur. J. 2018, 24, 8774.

(13) (a) Neary, M. C.; Quinlivan, P. J.; Parkin, G. Inorg. Chem. 2018, 57, 374. (b) Koch, F.; Berkefeld, A. Dalton Trans. 2018, 47, 10561. (c) Tolman, C. A. Inorg. Chem. 1972, 11, 3128.

(14) (a) Ohmura, N.; Nakamura, A.; Hamasaki, A.; Tokunaga, M. Eur.J. Org. Chem. 2008, 2008, 5042. (b) Zacuto, M. J.; Xu, F. J. Org. Chem. 2007, 72, 6298. (c) Kamijo, S.; Huo, Z.; Jin, T.; Kanazawa, C.; Yamamoto, Y. J. Org. Chem. 2005, 70, 6389. (d) Garro-Helion, F.; Merzouk, A.; Guibé, F. J. Org. Chem. 1993, 58, 6109.

(15) Hayakawa, Y.; Wakabayashi, S.; Kato, H.; Noyori, R. J. Am. Chem. Soc. 1990, 112, 1691.

(16) 2-Methoxyphenol (2a): Typical Procedure In a glove box, a flame-dried $15 \mathrm{~mL}$ Schlenk tube was charged with $\left[\mathrm{Ni}\left(\mathrm{PMe}_{3}\right)_{4} \mathrm{H}\right] \mathrm{N}\left(\mathrm{SO}_{2} \mathrm{CF}_{3}\right)_{2}(1.6 \mathrm{mg}, 2.48 \mu \mathrm{mol}, 1 \mathrm{~mol} \%)$. The Schlenk tube was removed from the glove box and anhyd THF (1.5 mL, 0.16 M) was added. 1-(Allyloxy)-2-methoxybenzene (1a; $41.1 \mathrm{mg}, 0.250 \mathrm{mmol}, 1$ equiv) was then added under an argon counterflow and the mixture was stirred at RT for $30 \mathrm{~min}$. $\mathrm{TsOH} \cdot \mathrm{H}_{2} \mathrm{O}$ ( 1 equiv) was added, and the mixture was refluxed for $1 \mathrm{~h}$. The reaction was quenched by addition of EtOAc $(2 \mathrm{~mL})$ and $\mathrm{H}_{2} \mathrm{O}(2 \mathrm{~mL})$, and the mixture was transferred to a separatory funnel. The aqueous phase was extracted with EtOAc $(3 \times 5 \mathrm{~mL})$, and the combined organic phases were dried $\left(\mathrm{MgSO}_{4}\right)$. Rotary evaporation gave pure $\mathbf{2 a}$, without any chromatographic purification, as a light-brown oil; yield: $26.1 \mathrm{mg}(0.21 \mathrm{mmol}, 84 \%)$. The NMR spectral data matched those reported in the literature. ${ }^{17}$ Note: The glove box setup for the reaction is not necessary: the catalyst can be stored on the bench under an inert atmosphere.

(17) Song, L. X.; Wang, H. M.; Yang, Y.; Xu, P. Bull. Chem. Soc. Jpn. 2007, 80, 2185. 